\title{
Influence of Drying on the Characteristics of Zinc Oxide Nanoparticles
}

\author{
C.P. Rezende ${ }^{1}$, J.B. da Silva ${ }^{1,2}$, N.D.S. Mohallem ${ }^{1 *}$ \\ ${ }^{1}$ Laboratório de Materiais Nanoestruturados, Departamento de Química, ICEx UFMG and \\ ${ }^{2}$ Centro de Desenvolvimento da Tecnologia Nuclear - CDTN/CNEN 31270-901 Belo Horizonte-MG, Brazil
}

(Received on 1 July, 2008)

\begin{abstract}
The recent growth in the field of porous and nanometric materials prepared by non-conventional processes has stimulated the search of new applications of $\mathrm{ZnO}$ nanoparticulate. Zinc oxide is an interesting semiconductor material due to its application on solar cells, gas sensors, ceramics, catalysts, cosmetics and varistors. In this work, the precipitation method was used followed by controlled and freezing drying processes. The materials obtained were thermally treated at various temperatures. The influence of temperature on structural, textural, and morphological properties of the materials was studied by powder X-ray diffraction, infrared spectroscopy, scanning electron microscopy, nitrogen adsorption, and thermal analysis. The characteristics of both materials were compared.
\end{abstract}

Keywords: zinc oxide, drying process, nanoparticle

\section{INTRODUCTION}

Zinc oxide is a versatile material due to properties such as: pyroelectricity, semiconducting, piezoelectricity, luminescence, and catalytic activity $[1-2]$. Its optical band gap, chemical and thermal stabilities are also very important characteristic. These properties are essential for electronic and photonic industry due to the wide range of technological applications in devices including acoustic surface, wave filters, sensors, transparent conductors, light-emitting diodes, laser diodes, solar energy conversion [3-5], electro-acoustic transducers, photovoltaic devices, catalysts and varistors [6-8]. Zinc oxide powders are also a commercially important material utilized in paints and rubber [9].

The properties of $\mathrm{ZnO}$ depend mainly of the crystallite size and morphology [10]. With the objective to prepare $\mathrm{ZnO}$ nanostructures with desire properties, some methods are used, such as the sol-gel process [11], hydrothermal route, chemical vapor deposition, homogeneous precipitation and electrodeposition. Farley et al produced $\mathrm{ZnO}$ from zinc acetate as precursor, getting a high quality semiconductor oxide for various technical applications [12]. The hydrothermal process was used to obtain different structures of $\mathrm{ZnO}[13]$. $\mathrm{ZnO}$ nanoparticulate was prepared by solid state reaction at low temperature of calcination $\left(500{ }^{\circ} \mathrm{C}\right)$ through thermal decomposition, [14]. The evolution of the microstructure during the formation of $\mathrm{ZnO}$ powder particles obtained by the freezedrying method was investigated by Marinkovic et al [15]. These syntheses allowed to the preparation of $\mathrm{ZnO}$ with a variety of morphologies, including nanoparticles, nanowire, nanorod, nanoribbon, nanoplate, nanotube, multipods, etc $[16-18]$.

In this work the precipitation process was used to obtain $\mathrm{ZnO}$ particles by reaction between aqueous solutions of $\mathrm{Zn}\left(\mathrm{NO}_{3}\right)_{2}$ and $\mathrm{Na}_{2} \mathrm{CO}_{3}$. The textural, microstructural, and morphological characteristics were investigated to establish the correlation between the powder characteristics with the drying type and the calcination temperature.

\footnotetext{
*Electronic address: nelcy@ufmg.br
}

\section{EXPERIMENTAL}

Zinc nitrate and sodium carbonate were used as precursors of the $\mathrm{ZnO}$ particles. In a typical synthesis, $\mathrm{Zn}\left(\mathrm{NO}_{3}\right)_{2} \cdot 6 \mathrm{H}_{2} \mathrm{O}$ were dissolved in deionized water in the molar ratio of 1:5, and mixed for homogenization during $1 \mathrm{~h} . \mathrm{Na}_{2} \mathrm{CO}_{3}$ were also dissolved in deionized water in the molar ratio of 7:10, and mixing with the zinc solution leading to the formation of a white precipitate. The precipitate was washed with deionized water to remove impurities. The obtained powder was separated in two aliquots to be submitted to drying processes. One aliquot $(S 1)$ was dried in an oven at $110^{\circ} \mathrm{C}$ for $48 \mathrm{~h}$ and the other $(S 2)$ was immersed in liquid nitrogen to freezing and then was lyophilized by $78 \mathrm{~h}$ at $-40{ }^{\circ} \mathrm{C}$ and vacuum of 0.7 $\mathrm{Pa}$. Both the aliquots were calcined at different temperatures between 200 and $1000^{\circ} \mathrm{C}$ for 2 hours.

Simultaneous thermogravimetric and differential thermal analysis $(T G-D T A)$ measurements were performed (TAInstrumentSDT2960). The samples were heated from room temperature up to $1100^{\circ} \mathrm{C}$ at $10^{\circ} \mathrm{C} \cdot \mathrm{min}^{-1}$ under airflow.

All samples were analyzed by X-ray diffractometry (Rigaku,Geigerflex3034) with $\mathrm{CuK} \alpha$ radiation, $40 \mathrm{kV}$ and $30 \mathrm{~mA}$, time constant of $0.5 \mathrm{~s}$ and crystal graphite monochromator. Crystallite size was determined by Scherrer equation $(D=0.9 \lambda / \beta \cos \theta$, where $D$ is the crystallite diameter, $\lambda$ is the radiation wavelength and $\theta$ the incidence angle) [17]. The value of $\beta$ was determined from the experimental integral peak width with silicon as a standard. Values were corrected for instrumental broadening.

Infrared spectroscopy (Perkin-Elmer,2838) was used to evaluate the chemical modifications of $\mathrm{ZnO}$ powders heated at different temperatures. The morphology of the composites was evaluated by scanning electron microscopy $(J E O L-J S M 840 A)$. The textural characteristics of the samples were determined through nitrogen gas adsorption ( $\mathrm{Au}-$ tosorb - Quantachrome Nova 1200) at liquid nitrogen temperature. Nitrogen gas was used with a 22-point adsorptiondesorption cycle. The samples were outgassed at $200^{\circ} \mathrm{C}$ for 3 $\mathrm{h}$ before each analysis. Specific surface areas and total pore volumes were obtained by the application of the BrunauerEmmett-Teller $(B E T)$ equation and the BJH method. The particle size of the powders was evaluated using the equation: $d(n m)=6 / S \cdot \rho$, where 6 is the form factor for spherical or cubic particles, $S$ is the superficial area in $\mathrm{m}^{2} \mathrm{~g}^{-1}$ and $\rho$ is the 
true density in $\mathrm{g} \mathrm{cm}^{-3}$.

\section{RESULTS AND DISCUSSION}

TG curve for the S1 sample (Fig.1a) shows three stages of weigh loss accompanied by two endothermic and two exothermic peaks in DTA curve. The first endothermic event between 100 and $200^{\circ} \mathrm{C}$ can be associated to removal of surface water of the sample with weight loss of $18 \%$. The weight lost of $2 \%$ in the range of $210-380^{\circ} \mathrm{C}$, accompanied by one endothermic and one exothermic peak, and of $2 \%$ in the range of $410-800^{\circ} \mathrm{C}$ is due to the nitrate and $\mathrm{CO}_{3}$ decomposition. The broad and intense exothermic peak could be associated with the formation of the pure $\mathrm{ZnO}$ phase. The obtained residue is around $78 \%$ (pure $\mathrm{ZnO}$ phase).
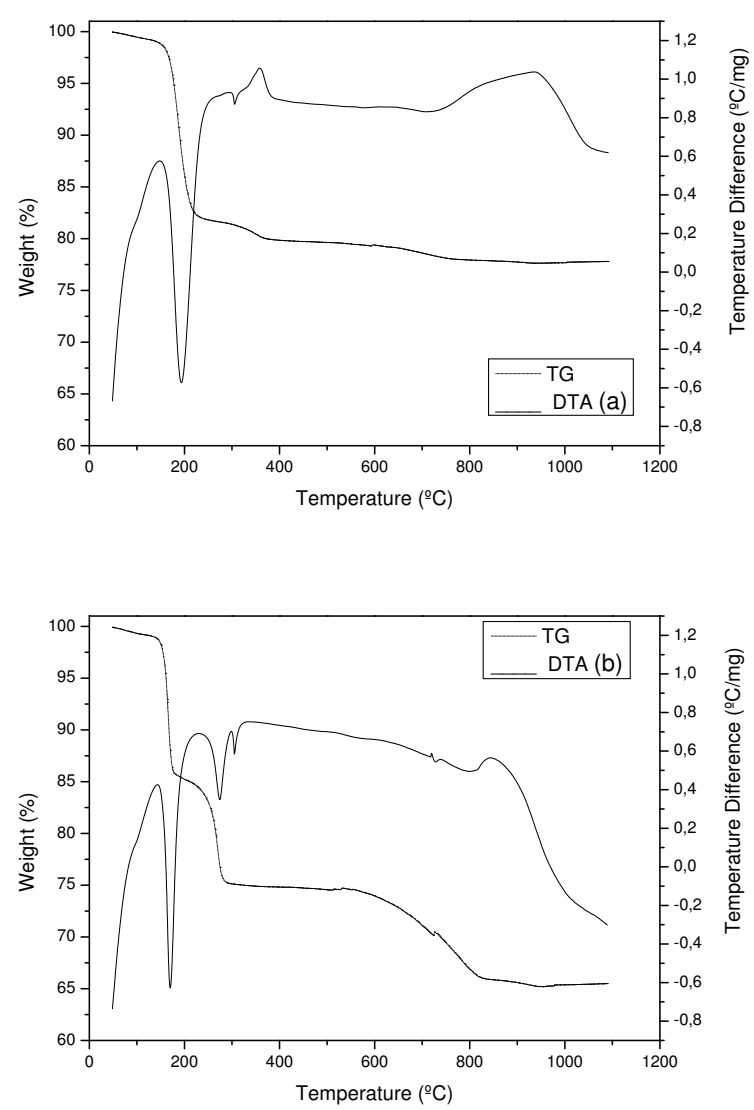

FIG. 1: TG/DTA curves of $\mathrm{ZnO}$ previously dried at $110^{\circ} \mathrm{C}$, (a) controlled and (b) freeze drying.

The $\mathrm{S} 2$ sample (Fig. 1 b) lost $14 \%$ weight in the range of 50$180^{\circ} \mathrm{C}$ due to surface water removal related to an endothermic event. The other two endothermic events between $180-250^{\circ} \mathrm{C}$ and $580-820^{\circ} \mathrm{C}$ were attributed to loss of sodium nitrate (11 $\%)$ and carbon dioxide (10\%). These events are accompanied by endothermic peaks in DTA curves. A broad exothermic event appears between 800 and $930^{\circ} \mathrm{C}$, probably due to the formation of the pure $\mathrm{ZnO}$ phase. In this case, the residue obtained is around $65 \%$. We can describe the $\mathrm{ZnO}$ formation with the reaction below:

$$
\begin{gathered}
\mathrm{Zn}\left(\mathrm{NO}_{3}\right)_{2} \cdot 6 \mathrm{H}_{2} \mathrm{O}+\mathrm{Na}_{2} \mathrm{CO}_{3} \rightarrow \mathrm{ZnCO}_{3}+2 \mathrm{NaNO}_{3}+6 \mathrm{H}_{2} \mathrm{O} \\
\mathrm{ZnCO} \mathrm{O}_{3} \rightarrow \mathrm{ZnO}+\mathrm{CO}_{2} \uparrow
\end{gathered}
$$

Figures $2 \mathrm{a}$ and $2 \mathrm{~b}$ show XRD patterns of $\mathrm{S} 1$ and $\mathrm{S} 2$ samples calcined at various temperatures. The characteristic peaks of the $\mathrm{ZnO}$ phase increase in intensity above $200^{\circ} \mathrm{C}$ with the calcination temperature. The $\mathrm{S} 1$ sample presented peaks characteristics of $\mathrm{ZnO}$ phase at $200^{\circ} \mathrm{C}$ and by-products such as $\mathrm{NaNO}_{3}$ and $\mathrm{ZnCO}_{3}(4 \%)$, which decomposed gradually with increasing in the temperature. The pure phase of $\mathrm{ZnO}$ was formed below $800^{\circ} \mathrm{C}$.

The S2 sample shows peaks of $\mathrm{ZnO}$ phase with $21 \%$ of byproducts such as $\mathrm{ZnCO}_{3}$ and $\mathrm{NaNO}_{3}$ between 200 and $600^{\circ} \mathrm{C}$, which decomposed with the increase in the temperature, originating pure phase of $\mathrm{ZnO}$ above $800^{\circ} \mathrm{C}$.
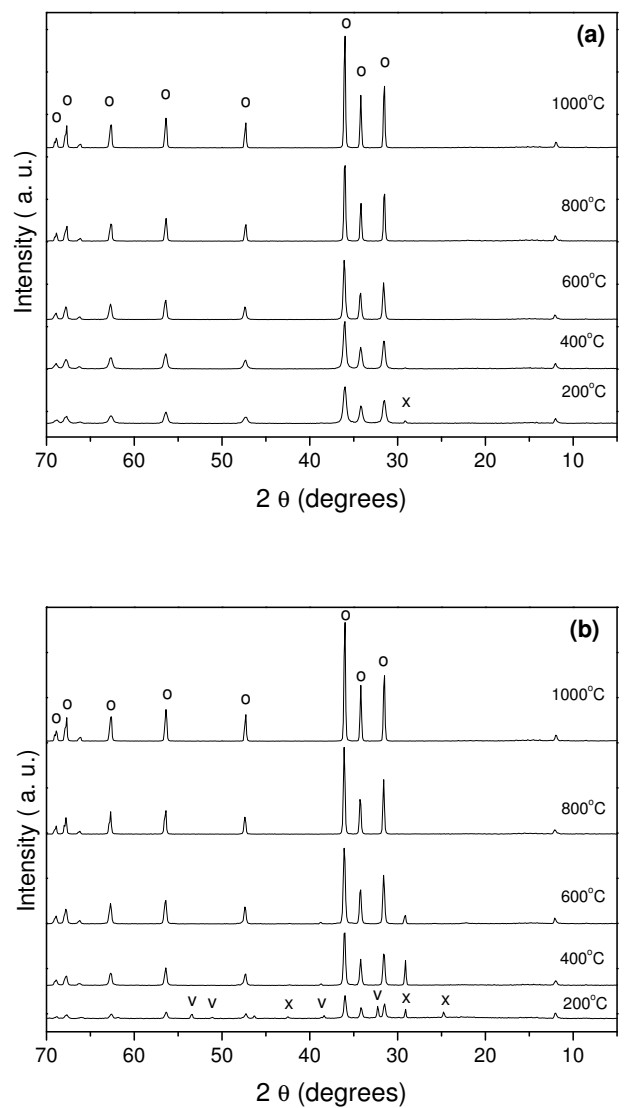

FIG. 2: X-ray diffraction patterns of $\mathrm{o}=\mathrm{ZnO}, \mathrm{x}=\mathrm{NaNO}_{3}$ and $\mathrm{v}=\mathrm{ZnCO}_{3}$ powders treated at different temperatures a) prepared by controlled drying (S1) and b) prepared by freeze drying (S2).

Figure 3 shows infrared spectra of the $\mathrm{ZnO}$ samples ( $\mathrm{S} 1$ and $\mathrm{S} 2$ ) treated at various temperatures. The spectra show bands $\left(3500 \mathrm{~cm}^{-1}\right)$ assigned to $\mathrm{OH}^{-}$stretching vibrations of crystalline and adsorbed $\mathrm{H}_{2} \mathrm{O}$. Two bands were observed at 1512 and $1365 \mathrm{~cm}^{-1}$, corresponding to $v_{3}$ frequency of carbonate groups $(\mathrm{C}-\mathrm{O}$ and $\mathrm{C}=\mathrm{O})$. In the spectra of $\mathrm{S} 1$ sample, these bands disappear after treatment at $600^{\circ} \mathrm{C}$ and in $\mathrm{S} 2$ spectra only after $800^{\circ} \mathrm{C}$. Bands at $1050 \mathrm{~cm}^{-1}, 835 \mathrm{~cm}^{-1}$ and $703 \mathrm{~cm}^{-1}$ relate to $v_{1}, v_{2}$, and $v_{4}$ frequencies of the carbonate 
appear in S1 spectra only for treatment at $110^{\circ} \mathrm{C}$ and in $\mathrm{S} 2$ spectra until treatment at $800^{\circ} \mathrm{C}$. Bands with small intensity characteristics of nitrate groups appear at $1630 \mathrm{~cm}^{-1}$. These bands disappear only above heating at $800^{\circ} \mathrm{C}$. The $\mathrm{S} 1$ spectra show a broad band between 550 and $465 \mathrm{~cm}^{-1}$ with shoulder shape, characteristic of hexagonal $\mathrm{Zn}-\mathrm{O}$ phase. With the increasing in the calcination temperature, the shoulder shape changes and a unique broad band is formed. The S2 spectra also show a broad band, without the shoulder shape, more intense than the S1 sample ones. According to literature [18], the shape of the IR bands can be due to the geometry and size of the particles, and/or the aggregate formation.
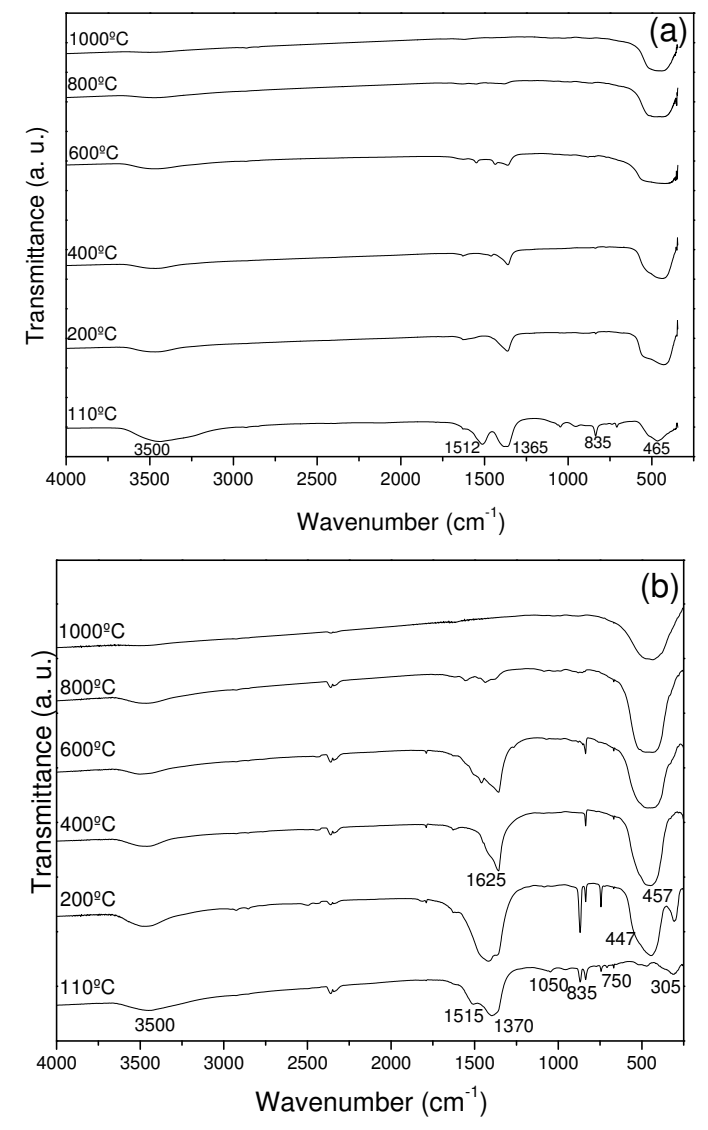

FIG. 3: Infrared spectra of $\mathrm{ZnO}$ powders treated at different temperatures a) prepared by controlled drying (S1) and b) prepared by freeze drying (S2).

The IR spectra show that the S2 sample has more impurities than the $\mathrm{S} 1$ sample, according to XRD patterns and TG/DTA curves, confirming the difference between the powders produced in both the process.

Figure 4 shows the morphology of the $\mathrm{ZnO}$. The images obtained by SEM of the S1 samples treated at $110^{\circ} \mathrm{C}($ Fig $4 a)$ show plate-like nanoparticles forming agglomerates. After treatment at $800^{\circ} \mathrm{C}$, these particles (Fig.4b) grow and densify, reaching an average particle size of $0.550 \pm 0.050 \mu \mathrm{m}$. The S2 images (Fig. 4c) also shows plate-like nanoparticles, which grow after treatment at $800^{\circ} \mathrm{C}($ Fig.4d), reaching an average particle size of $1.1 \pm 0.1 \mu \mathrm{m}$. The samples showed significant morphological differences.

Table 1 shows the textural characteristics of $\mathrm{ZnO}$ samples

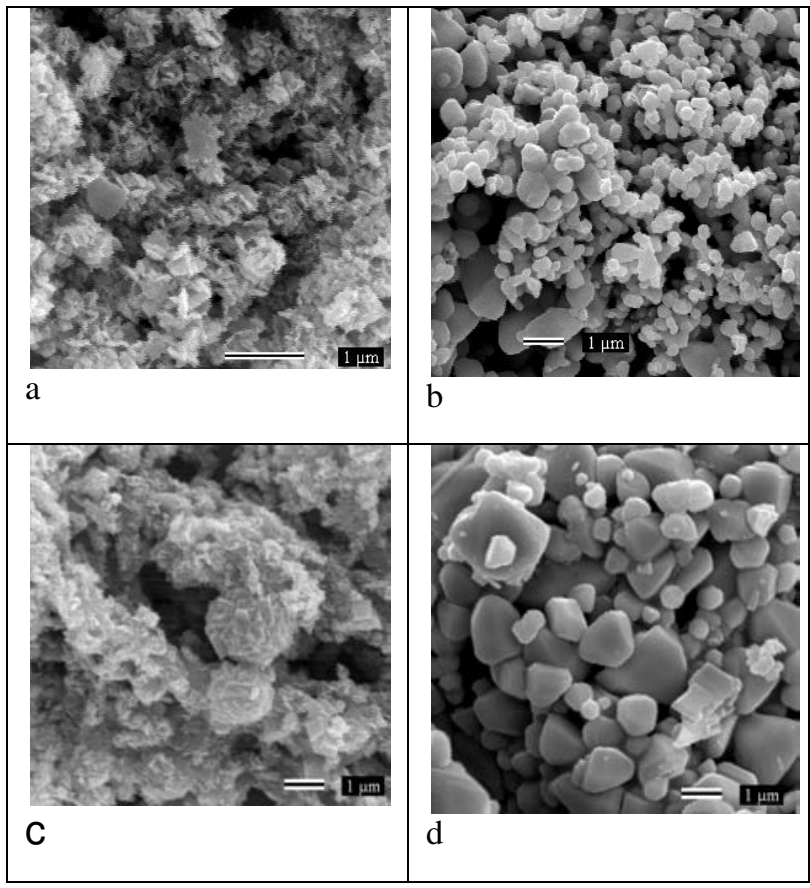

FIG. 4: Images of $\mathrm{ZnO}$ powders treated at different temperatures a) $\left.\left.\mathrm{S} 1-100^{\circ} \mathrm{C}, \mathrm{b}\right) \mathrm{S} 1-800^{\circ} \mathrm{C}, \mathrm{c}\right) \mathrm{S} 2-100^{\circ} \mathrm{C}$ and d) S2 $-800^{\circ} \mathrm{C}$.

Table 1 - Textural and morphological characteristics of the $\mathrm{ZnO}$ nanoparticles.

\begin{tabular}{cccccc}
\hline $\begin{array}{c}\text { Temperature } \\
\left({ }^{\circ} \mathrm{C}\right)\end{array}$ & $\begin{array}{c}\text { SSA } \\
\left(\mathrm{m}^{2} \mathrm{~g}^{-1}\right)\end{array}$ & $\begin{array}{c}\text { True } \\
\text { Density } \\
\left(\mathrm{g} . \mathrm{cm}^{-3}\right)\end{array}$ & $\begin{array}{c}\text { Total pore } \\
\text { volume } \\
\left(10^{-3} \mathrm{~cm}^{-3} \mathrm{~g}^{-1}\right)\end{array}$ & $\begin{array}{c}\text { Average } \\
\text { particle } \\
\text { size } \\
(\mathrm{nm})\end{array}$ & $\begin{array}{c}\text { Average } \\
\text { crystallite } \\
\text { size by } \\
\text { XRD(nm) }\end{array}$ \\
\hline \multicolumn{6}{l}{ Controlled drying } \\
\hline 110 & 39.1 & 3.8 & 48 & 40 & 12 \\
200 & 27.2 & 3.9 & 35 & 57 & 29 \\
400 & 17.1 & 4.2 & 23 & 84 & 35 \\
600 & 7.2 & 4.5 & 10 & 185 & 45 \\
800 & 2.1 & 4.8 & 2 & 595 & 64 \\
\hline Freeze drying & & & & & \\
\hline As-prepared & 20.1 & 2.5 & 31 & 119 & 46 \\
200 & 7.2 & 3.0 & 8 & 278 & 35 \\
400 & 2.0 & 3.3 & 1 & 909 & 66 \\
600 & 1.5 & 3.8 & 2 & 1051 & 82 \\
800 & 1.0 & 5.0 & 2 & 1200 & 91 \\
\hline
\end{tabular}

treated at various temperatures. S1 samples had specific surface area, porosity and true density larger than S2 samples. We also can observe that the average particle size measured by BET method is according to the results obtained by SEM.

Figure 5 shows the adsorption-desorption isotherms for samples S1 treated at different temperatures. The material has characteristic of no-porous nanoparticulate material only until heating temperatures of $600^{\circ} \mathrm{C}$. (type II isotherm, according to BDDT [19] classification). The hysteresis type H3 is associated with a closure of the hysteresis loop due to the so-called tensile strength effect, provoked by particles platelike, according to the SEM images. This characteristic disappears with the increase in the heating temperature due to the growth and densification of the particles. 


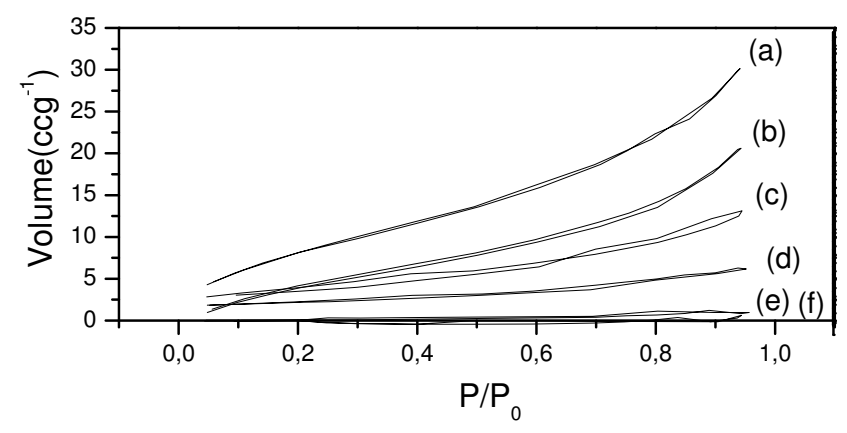

FIG. 5: Adsorption-desorption isotherms of $\mathrm{ZnO}$ nanoparticles (Sl) treated at different temperatures: (a) $110^{\circ} \mathrm{C}$, (b) $200^{\circ} \mathrm{C}$, (c) $400^{\circ} \mathrm{C}$, (d) $600^{\circ} \mathrm{C}$, (e) $800^{\circ} \mathrm{C}$ and f) $1000^{\circ} \mathrm{C}$.

The freeze drying materials showed irregular isotherm curves (not shown), with $\mathrm{C}$ constant negative, characteristic of small interaction of the nitrogen with the material. We observed that the nitrogen did not wet the $\mathrm{ZnO}$ surface, showing that this kind of drying change significantly the surface sample, confirming the IR results.

\section{CONCLUSION}

The as-prepared zinc oxide obtained by controlled temperature $(S 1)$ was more pure than $\mathrm{ZnO}$ powder obtained by freeze drying $(S 2)$. These impurities were eliminated with the increasing in the calcination temperature but influenced drastically the morphological and textural characteristics of the final product. All the samples calcined at $800^{\circ} \mathrm{C}$ had the same structure but with different particle size and surface characteristic.

\section{ACKNOWLEDGEMENT}

This work was supported by CNPq and CAPES.
[1] Y. Ni, X. Cao, G.Wu, G.Hu, Z. Yang and X. Wei, Nanotechnology, 18, 1 (2007).

[2] K. M Parida; S. S. Dash and D. P. Dash, Journal of Colloid and Interface Science, 298, 787 (2006).

[3] H. Cheng, J. Cheng, Y. Zhang and Q. Wang, Journal of Crystal Growth, 299, 34 (2007).

[4] S. Dutta, S. Chattopadhyay and D. Jana, Journal of Applied Physics, 100, 114328 (2006).

[5] L. Schmidt-Mende. and J. MacManus-Driscoll, J., Materials Today, 10, n.5, 40 (2007).

[6] M. Zunic, Z. Brankovic, S. Bernik, M. S. Góes and G. Brankovic, Journal of the European Ceramic Society, 27, 3897(2007).

[7] E.M. El-Melinegy, H.I Saleh,. and M. Selim, Materials Characterization,.52, 371 (2004).

[8] M. Jitianu and A. V Goia, Journal of Colloid and Interface Science, 309, 78 (2007).

[9] G. S. Brady, H. R. Clauser and J. A Vaccari, Materials Handbook, Fourteenth Edition, Mc Graw-Hill, (1997).

[10] S. Music, D. Dragcevic; S. Popovic, Journal of Alloys and Compounds, 429, 242 (2007).
[11] Y.P. Gao, C. N. Sisk and L. J. Hope-Weeks, Chemistry of Materials, 19, 6007 (2007).

[12] N. R. S. Farley, C. R. Staddon et al, J. of Materials Chemistry, 14, 1087 (2004).

[13] Y. S. Fu, X. Du, J. Sun, Y. Song and J. Liu, J. Phys. Chem. C, 111,3863 (2007)

[14] H. Zhang; G. Cheng, G. Yang, J. Zhang and X. Lu, J. Mater Sci: Mater Electron, 18, 381 (2007).

[15] Z.V.Marinkovic, O Milosevic et al, Materials Science and Engineering A, 375, 620 (2004).

[16] Z.L. Wang, Journal of Physics Condensed Mater, 16, R829 (2004).

[17] R. Jenkins and R. L.Snyder, Introduction to X-Ray Powder Diffractometry in Chemical Analysis, 138, John Wiley \& Sons, Inc (1996).

[18] S. Music, A.Saric and S. Popovic, Journal of Alloys and Compounds, 448, 277 (2008).

[19] S.J. Greg, K.S.W. Sing. Adsorption, Surface Area and Porosity (2002). 